\title{
Corrigendum: Association of DOCK8, IL17RA, and KLK12 Polymorphisms with Atopic Dermatitis in Koreans
}

Won Il Heo, Kui Young Park, Mi-Kyung Lee ${ }^{1}$, Yu Jeong Bae, Nam Ju Moon², Seong Jun Seo

Departments of Dermatology, ${ }^{1}$ Laboratory Medicine, and ${ }^{2}$ Ophthalmology, Chung-Ang University Hospital, Seoul, Korea

Ann Dermatol 2020;32(3):197-205

https://doi.org/10.5021/ad.2020.32.3.197

We found that the Acknowledgment in article above was published incorrectly.

The corrected version should be as follows:

\section{ACKNOWLEDGMENT}

This study was supported by the National Research Foundation of Korea (NRF) grant funded by the Korea government (MSIT) (No. 2019R1A2C1090226). This research was supported by the Chung-Ang University Research Scholarship Grants in 2018.

We sincerely apologize for any confusions that we may have caused.

This is an Open Access article distributed under the terms of the Creative Commons Attribution Non-Commercial License (http://creativecommons.org/ licenses/by-nc/4.0) which permits unrestricted non-commercial use, distribution, and reproduction in any medium, provided the original work is properly cited.

Copyright $\odot$ The Korean Dermatological Association and The Korean Society for Investigative Dermatology 